\section{Blood-aqueous barrier integrity in patients with Graves' ophthalmopathy (GO), before and after rehabilitative surgery}

A Kłysik $^{1}$ and M Kozakiewicz ${ }^{2}$
${ }^{1}$ Department of

Ophthalmology, Medical University of Lodz, Lodz, Poland

\section{${ }^{2}$ Department of} Maxillofacial Surgery, Medical University of Lodz, Lodz, Poland

Correspondence: A Kłysik, Department of Ophthalmology, Medical University of Lodz, Żeromskiego 113, Lodz 90-549, Poland Tel: +48 42608653 720; Fax: +48 426393634.

E-mail: anna.klysik@ umed.lodz.pl

Received: 5 August 2014 Accepted: 10 December 2014

Published online:

13 February 2015

\begin{abstract}
Purpose The study was conducted to analyze aqueous flare and its correlations in patients with Graves' ophthalmopathy (GO) undergoing orbital decompression, extraocular muscle, and eyelid surgery. Prospective interventional case series. Patients and Methods Forty-eight eyes of 27 patients ( 20 female and 7 male, aged $54.4 \pm 5.7)$ undergoing surgical treatment for GO. Eighteen eyes of nine patients (aged $55.3 \pm 3.6)$ undergoing orbital decompression. Nineteen eyes of 11 patients (aged $54.7 \pm 5.6$ ) undergoing extraocular muscle surgery and 13 eyes of 7 patients (aged $53.9 \pm 4.9$ ) undergoing eyelid surgery and control group (34 patients aged 53.9 \pm 5.1 ). Laser flare analysis and clinical assessment were performed before surgery and at 1 day, 7 days, and 3 months following surgery. Results Aqueous flare was significantly higher in patients with GO (14.03 \pm 8.45) before intervention than in the control group (7.89 \pm 3.56$)(P<0.001)$, and correlated with Clinical Activity Score and intraocular pressure. In the patients undergoing orbital decompression, flare increased from $17.77 \pm 10.63 \mathrm{pc} / \mathrm{ms}$ to $38.32 \pm 13.56 \mathrm{pc} / \mathrm{ms}$ on the first day and $41.31 \pm 17.19 \mathrm{pc} / \mathrm{ms}$ on the seventh day and returned to $16.01 \pm 8.58 \mathrm{pc} / \mathrm{ms}$ in 3 months. In patients undergoing extraocular muscle surgery flare increased from $13.05 \pm 6.50$ to $23.04 \pm 11.53 \mathrm{pc} / \mathrm{ms}$ $(P<0.001)$ on the first day and returned to $18.02 \pm 14.09 \mathrm{pc} / \mathrm{ms}$ on the seventh day. Eyelid surgery did not change flare values.
\end{abstract}

Conclusions Orbital decompression disrupts blood-aqueous barrier (BAB). The integrity of $B A B$ returns to preoperative status within 3 months. Extraocular muscle surgery mildly affects $B A B$ integrity, and the effect subsides within 7 days. Eyelid surgery does not affect BAB.

Eye (2015) 29, 542-551; doi:10.1038/eye.2014.337; published online 13 February 2015

\section{Introduction}

Graves' ophthalmopathy (GO) is a chronic, autoimmune, inflammatory orbital disease, which causes increase in volume and swelling of the soft orbital tissue behind the globe, resulting in proptosis, myopathy, compressive optic neuropathy, and corneal exposure in varying degree. ${ }^{1}$ Disease begins with an active inflammatory stage, which is followed by an inactive fibrotic stage. ${ }^{2}$ Surgical treatment for GO is used in cases with severe exophthalmos, optic nerve compression, severe restrictive myopathy, and upper and lower eyelid retraction. ${ }^{3}$

Aqueous flare reflects protein content in the aqueous humour of the anterior chamber of the eye. Physiological protein content is up to $1 \%{ }^{4}$ It filtrates from the ciliary body capillaries and passes into the anterior chamber through iris stroma, reflecting the integrity of tight junctions forming blood-aqueous barrier (BAB) ${ }^{5}$

Laser flare photometry represents noninvasive, objective, and quantitative method to assesBAB integrity and also allows to assess accurately subclinical pathologies. ${ }^{6}$ The changes 
of BAB have been studied in variety of ocular diseases such as uveitis, ${ }^{7}$ acute and chronic angle closure glaucoma, ${ }^{8}$ non-inflammatory disease, ${ }^{9}$ and topical medication use. ${ }^{10}$ Also it was used to compare the influence on $\mathrm{BAB}$ of surgical intraocular procedures ${ }^{11}$ and laser procedures. ${ }^{12}$

GO involves orbital, extraocular tissue, nevertheless intraocular complications such as increased intraocular pressure (IOP), choroidal folds, swelling of the optic nerve head, and corneal astigmatism may result. ${ }^{13,14}$ There is a possibility that subclinical disruption of BAB may be present as a result of inflammatory process within the orbit or subclinical intraocular inflammatory changes.

$\mathrm{BAB}$ consists of tight junctions between the cells of the ciliary epithelium and tight junctions of the iris blood vessels. ${ }^{5}$ Proteins diffuse from the capillaries of ciliary body stroma into the iris stroma, where a reservoir forms, and into the anterior chamber. Alterations of aqueous humour protein concentrations are possible without inflammation and disruption of the tight junctions, as is the situation in antiglaucoma medication use, ${ }^{15}$ where diminished aqueous production causes increase in the protein content in the anterior chamber. Increased protein content of the $\mathrm{AC}$ has been demonstrated in several types of glaucoma. IIOP increase is one of the well-recognized features of $\mathrm{GO}^{16}$ and regarded to be secondary to elevated episcleral venous pressure. ${ }^{17}$ As aqueous protein content, out-flow resistance, and IOP are inter-related, ${ }^{18}$ therefore the authors assumed that $\mathrm{BAB}$ integrity in GO might also be affected for this reason.

Reconstructive procedures following Graves' orbitopathy include orbital decompression, extraocular muscle surgery, ${ }^{19}$ and eyelid surgery. Orbital decompression is effective in reducing proptosis, corneal exposure, and improving cosmetic appearance; however, it carries a risk of serious complications, such as bleeding, infection, or cerebrospinal fluid leakage. ${ }^{20}$ It has recently been proven that it has lowering effect on IOP and no effect on refraction and corneal astigmatism. ${ }^{21}$ We assumed that orbital decompression may also influence intraocular homeostasis.

Extraocular muscle surgery is adopted to relieve diplopia, abnormal head position, and cosmetically unacceptable squint, associated with restrictive myopathy. ${ }^{22}$ Extraocular muscle surgery carries the risk of anterior segment ischemia, which increases with the number of muscles being operated on in the same eye. Anterior chamber ischemia would be expected to cause BAB breakdown. ${ }^{23}$ Although BAB has been demonstrated to remain unchanged during squint surgery in children, ${ }^{24}$ the effects of surgery to relieve extraocular muscle restriction in GO are not known.

Eyelid surgery is regarded as relatively safe in respect of anterior and posterior segment ocular complications, and it is intriguing if this is confirmed with the aqueous flare analysis.

The aim of this study was to assess BAB integrity by means of aqueous flare laser photometry in the patients with GO before and after surgical rehabilitative procedures.

\section{Materials and methods}

The study was approved by the Ethics Committee of the Medical University of Lodz and conducted according to the declaration of Helsinki between January 2012 and April 2014. All patients were informed about the noninvasive nature of the investigation and gave their full informed consent. Forty-eight eyes of 27 patients (20 female and 7 male, aged 54.4 \pm 5.7 ) who underwent first time surgical treatment for $\mathrm{GO}$ were included into the study. Two patients were excluded. General and ophthalmic history was obtained. Full ophthalmic examination and evaluation of ophthalmopathy including exophthalmos, clinical activity score (CAS), and muscle restrictions were carried out. ${ }^{25}$ Laser flare photometry was performed before surgical treatment in all the patients in the study undergoing orbital decompression (group A), extraocular muscles surgery (group B), and eyelid surgery (group C). Control group consisted of 34 sex, age, IOP, and IOP treatment-matched volunteers recruited from outpatient eye clinic, without history of thyroid disease, with normal thyroid function tests, no history of ocular or orbital surgery, except uncomplicated phacoemulsification and no ocular pathology except mild lens opacity and ocular hypertension on IOP-lowering medication. It was not feasible to match control group in respect of smoking.

Thyroid hormones (FT3, FT4) and thyroid-stimulating hormone (TSH) and anti-TSH antibodies (TRAb) were measured using commercial methods. Patients included in the study were euthyroid before surgery. Orbitopathy has been confirmed by magnetic resonance imaging (MRI) and history of the orbitopathy obtained from the clinical records. MRI confirmed that all but one patient were in an inactive stage of Graves' disease.

Ophthalmic evaluation included history of eye disease and family history of eye disease, visual acuity testing, IOP measurement with Goldman applanation tonometry and Tonopen, slit lamp examination of the anterior chamber, and fundoscopy using +90 D lens, and slit lamp. IOP was measured with two methods to eliminate gaze-dependent rises in IOP related with extraocular muscle restrictions. If the difference between the two measurements was $2.0 \mathrm{~mm} \mathrm{Hg}$ or less, average of the two readings was taken into account. If the difference was $>2.0 \mathrm{~mm} \mathrm{Hg}$, measurement was repeated with the Tonopen in the direction of gaze opposite to the 
maximum restriction. The three lowest readings were averaged and taken into the analysis. Evaluation of ophthalmopathy included onset and duration of Graves' disease, onset and duration of Graves' ophthalmopathy, and previous forms of treatment. History of ophthalmopathy included intensity of inflammatory signs, IOP, and history of optic nerve compression and corneal exposure. Exophthalmos was measured with Hertel's exophthalmometer. Ocular ductions and versions were noted. Limitations of ductions in each direction were graded in the five-point scale (0-4) and noted. Direction in which ocular motility was most restricted was noted and analyzed as a restrictive myopathy score. Palpebral fissure was measured with the patient looking straight ahead. Photographic documentation was obtained, and MRI was performed just before the surgical treatment.

Baseline aqueous flare was measured 1-3 days before planned surgery, on the first day after surgery, and 7 days and 3 months following surgery. Visual acuity was tested on the seventh day postoperatively and 3 months postoperatively.

\section{Exclusion criteria}

Exclusion criteria were best-corrected visual acuity worse than 20/80 in either eye; corneal abnormalities; uncontrolled systemic disease; active ocular diseases other than glaucoma or ocular hypertension; diabetes; pigment dispersion syndrome, contact lens use; pregnancy, breastfeeding, history of ocular injury or uveitis; previous ocular surgery, other than uncomplicated phacoemulsification, laser treatment, and concomitant use of ocular medications, other than antiglaucomatous and artificial lubricants. Pseudoexfoliation and pseudophakia were not considered a reason for exclusion. Two patients were excluded; one because of previous glaucoma surgery and one because of poor visual acuity from high myopia. Patients who previously underwent any rehabilitative surgical procedure for GO were not eligible (eg, extraocular muscle surgery was a second step following decompression).

\section{Laser flare polarimetry}

The Laser-Flare-Cell-meter (KOWAFM 600) is the device for objective, quantitative, noninvasive, reproducible, in vivo evaluation of anterior segment protein content. Flare intensity is proportional to counts of aqueous proteins and is expressed as photon counts per millisecond ( $\mathrm{pc} / \mathrm{ms}$ ). No significant differences are found between right and left eye, between sexes or between irides of different colours. ${ }^{4,26}$ However, flare increases with age and decreases with pupillary dilatation. ${ }^{26}$ Normal values ${ }^{4}$ for the age groups $45-75$ are in the range of $4.0-5.5 \mathrm{ph} / \mathrm{ms}$.

Flare analysis was performed by a trained technician who was not aware of the nature of the disease nor the surgical procedure performed. Three reliable measurements were obtained each time, and average value was taken into account. No mydriatics were used.

\section{Orbital decompression (group A)}

Eighteen eyes of nine patients (aged 55.3 \pm 3.6 ) underwent orbital decompression, performed by the same surgeon (MK). Three patients underwent bony decompression only and five underwent both: bone and fat decompression simultaneously. One patient underwent fat decompression. Six patients underwent two wall decompression and two underwent three-wall decompression.

In general, anaesthesia trans-conjuctival approach was chosen to reach lower and medial orbital walls decompression. Both walls were removed by piezoelectric saw. Special attention was paid to save the infraorbital bundle during removal of lower part of infra-orbital canal and save the ethmoidal arteries. All procedures were performed in hypotension (mean arterial blood pressure $60-70 \mathrm{~mm} \mathrm{Hg}$ during ablative phase of procedure). When fat decompression was performed, the first step was over periorbital fat removal from four orbital compartments (two lower and two upper).

In one case, the three wall decompression was carried out. Coronal approach was used to expose anterior part of temporal spaces. Lateral wall was removed by piesoelectric saw, and orbital tissues were protected against pressure of temporalis muscle by convexly pre-bent titanium mesh. ${ }^{27,28}$ The mesh was screwed to surrounding bone. Additional orbital length increase was required in one case. Coronal approach was used. Orbital upper rim (2/3 laterally), lateral, (whole) and lower (2/3 laterally) were cut off and advanced. The new position of orbital rim was fixed by titanium microplates and $1.5 \mathrm{~mm}$ screws. That surgery was accomplished with fat and wall decompression. Conjunctiva was sutured with 7.0 polyglactin sutures. Periosteum and subcutaneous tissue was sutured by 4.0 polyglactin sutures and skin by 3.0 nonabsorbable, surgical monofilament suture composed of the long-chain aliphatic polyamide 6 .

\section{Extraocular muscle surgery (group B)}

Nineteen eyes of 11 patients (aged 54.7 \pm 5.6 ) underwent extraocular muscle surgery. Eight patients underwent bilateral surgery on two (four patients) or three (four 
patients) extraocular muscles and three patients underwent unilateral surgery on one (two patients) or two (one patient) extraocular muscles. Three patients underwent three muscle surgery in two eyes simultaneously, two medial recti and one inferior rectus muscle recession. Adjustable sutures were used in nine patients, seven underwent bilateral surgery and two underwent unilateral surgery and adjusted on the next morning, before flare analysis.

General anaesthesia was used in all cases. The procedure was performed either on the inferior rectus, medial rectus, or superior rectus muscle. Stay sutures were applied, and conjunctiva and Tenons' capsule were opened. Muscle was isolated, dissected, and recessed on average $3.8 \pm 1.3 \mathrm{~mm}$ (range from 2 to $7 \mathrm{~mm}$ ). Scleral sutures (6.0 polyglactin) were placed and either fixed or left on the loose knot to be adjusted on the second day. Conjunctiva was sutured with 6.0 polyglactin sutures.

\section{Eyelid surgery (group C)}

Thirteen eyes of seven patients (aged 53.9 \pm 4.9 ) underwent eyelid position surgery. Thirteen eyes underwent levator palpebrae recession and one eye also underwent lower eyelid retractors recession. Local anaesthesia in the form of 5-8 mls of $2 \%$ lidocaine was applied. Trans-palpebral approach was used. To recess upper eyelid levator, 6.0 poliglactin sutures were used. Skin was sutured with 6.0 nonabsorbable, braided suture.

\section{Statistical analysis}

Statistical analysis was performed in Statgtaphics Centurion XVI Version 16.1.03 by StatPoint Technologies, Inc. (Warrenton, VA, USA). Time-dependent change of aqueous flare laser photometry were made by $t$-test for paired samples as normal distribution presented, otherwise, when significant deviations from normality were detected, sign test was applied. Restrictive myopathy score was established as factor for ANOVA to evaluate its influence on aqueous flare values. KruskalWallis test was used in cases where variance check by Levene's test revealed significant difference among the SDs of samples. ANOVA was applied for comparison of aqueous flare laser photometry results depending on the type of surgical procedure. Pearson product moment correlations between each pair of variables were calculated. Simple regression analysis was made for assessment of the relation of maximum CAS value, exophthalmos (E), and IOPs with basal aqueous flare laser photometry record. A statistically significant difference was assumed for $P<0.05$.

\section{Results}

Demographical and ophthalmic data of the patients with GO and comparison with the control group are presented in Table 1. The data in three groups (A-orbital decompression surgery, B-extraocular muscles surgery, and C-eyelid surgery) with the flare values obtained in the course of the study are summarized in Table 2 .

Table 1 Demographic and ocular characteristics of Graves' Ophthalmopathy patients and controls

\begin{tabular}{|c|c|c|c|}
\hline & $\begin{array}{c}\text { Patients with Graves' Ophthalmopathy } \\
\text { (48 eyes of } 27 \text { patients) }\end{array}$ & $\begin{array}{c}\text { Control group } \\
\text { (68 eyes of } 34 \text { patients) }\end{array}$ & P-Value \\
\hline Age (years $\pm \mathrm{SD})$ & $54.4 \pm 5.7$ & $53.9 \pm 5.1$ & 0.75 \\
\hline Sex (F:M) & $20: 7$ & $23: 11$ & 0.86 \\
\hline Duration of GO (years \pm SD) & $5.7 \pm 2.1$ & - & - \\
\hline Thyroxine (\%) & 14 of 27 patients $(51.8 \%)$ & - & - \\
\hline Previous IV steroids (\%) & 20 of 27 patients $(74 \%)$ & - & - \\
\hline Previous GD treatment & & - & - \\
\hline Antithyroid (\%) & 25 of 27 patients $(92.6 \%)$ & & \\
\hline Thyroidectomy (\%) & 3 of 27 patients $(11 \%)$ & - & - \\
\hline Radioiodine $\left(\mathrm{I}^{131}\right)(\%)$ & 19 of 27 patients $(70.4 \%)$ & - & - \\
\hline Smoker or history of smoking (\%) & 18 of 27 patients $(66.6 \%)$ & 8 of $34(23.5 \%)$ & $0.00^{\mathrm{a}}$ \\
\hline Visual acuity (decimals) & $0.9 \pm 0.3$ & $0.9 \pm 0.2$ & 0.96 \\
\hline Maximum CAS $( \pm S D)$ & $4.05 \pm 1.8$ & - & \\
\hline Exophthalmos $(\mathrm{mm} \pm \mathrm{SD})$ & $21.05 \pm 4.13$ & $17.8 \pm 1.6$ & $0.00^{\mathrm{a}}$ \\
\hline Restrictive myopathy score ( $1-4 \pm \mathrm{SD})$ & $1.47 \pm 0.62$ & - & \\
\hline $\mathrm{IOP}(\mathrm{mm} \mathrm{Hg} \pm \mathrm{SD})$ & $20.02 \pm 4.30$ & $18.8 \pm 2.3$ & 0.07 \\
\hline IOP treatment $(\%)$ & $\begin{array}{c}10 \text { of } 27 \text { patients (37\%) (20 of } 48 \text { eyes) } \\
(41.6 \%)\end{array}$ & $\begin{array}{c}13 \text { of } 34 \text { patients }(38.2 \%) \text { (26 of } 68 \text { eyes) } \\
(38.2 \%)\end{array}$ & 0.63 \\
\hline Pseudophakia (\%) & 4 of 48 eyes $(8.3 \%)$ & 7 of 68 eyes $(10 \%)$ & 0.72 \\
\hline Palpebral fissure width (mm) & $12.0 \pm 1.1$ & $8.6 \pm 1.0$ & $0.00^{\mathrm{a}}$ \\
\hline Baseline flare (pc/ms) & $14.03 \pm 8.45$ & $7.89 \pm 3.54$ & $0.00^{\mathrm{a}}$ \\
\hline
\end{tabular}

a Statistically significant. 
Table 2 Characteristics of patients undergoing orbital decompression (A), extraocular muscles (B), and eyelid surgery (C), and flare values before surgery and 1 day, 7 days, and 3 months after surgery (F1, F2, F3)

\begin{tabular}{|c|c|c|c|}
\hline & A (18 eyes of 9 patients) & B (19 eyes of 11 patients) & $C$ (11 eyes of 7 patients) \\
\hline Age (years) & $55.3 \pm 3.6$ & $54.7 \pm 5.6$ & $53.9 \pm 4.9$ \\
\hline Sex (F:M) & $6: 3$ & $7: 4$ & $7: 0$ \\
\hline Duration of GO (years) & $5.7 \pm 2.1$ & $6.2 \pm 2.4$ & $4.6 \pm 3.2$ \\
\hline Thyroxine treatment & 5 of 9 patients & 5 of 11 patients & 4 of 7 patients \\
\hline Previous IV steroids & 9 of 9 patients & 9 of 11 patients & 2 of 7 patients \\
\hline \multicolumn{4}{|l|}{ Previous GD treatment } \\
\hline Antithyroid drugs & 9 of 9 patients & 10 of 11 patients & 6 of 7 patients \\
\hline Thyroidectomy & 2 of 9 patients & 1 of 11 patients & None \\
\hline$I^{131}$ & 7 of 9 patients & 8 of 11 patients & 4 of 7 patients \\
\hline Maximum CAS & $5.65 \pm 2.12$ & $4.35 \pm 2.62$ & $3.23 \pm 1.48$ \\
\hline Exophthalmos & $24.41 \pm 3.16$ & $20.24 \pm 2.05$ & $21.46 \pm 2.11$ \\
\hline Restrictive myopathy score (1-4) & $1.47 \pm 0.62$ & $3.00 \pm 0.00$ & $0.85 \pm 0.85$ \\
\hline IOP $(\mathrm{mm} \mathrm{Hg})$ & $21.53 \pm 6.60$ & $21.00 \pm 3.72$ & $20.85 \pm 4.08$ \\
\hline IOP treatment & 4 of 9 patients ( 8 of 18 eyes) & 6 of 11 patients ( 8 of 19 eyes) & none \\
\hline Pseudophakia & 2 of 18 eyes & 2 of 19 eyes & 1 of 13 eyes \\
\hline Palpebral fissure width (mm) & $13.4 \pm 1.5$ & $11.7 \pm 1.2$ & $12.3 \pm 0.8$ \\
\hline Baseline flare (pc/ms) & $18.25 \pm 10.76$ & $13.05 \pm 6.50$ & $10.14 \pm 4.95$ \\
\hline $\mathrm{F} 2(\mathrm{pc} / \mathrm{ms})$ & $38.41 \pm 13.98$ & $23.04 \pm 11.53$ & $10.57 \pm 4.12$ \\
\hline$P$-value (from baseline) & $0.00^{\mathrm{a}}$ & $0.00^{\mathrm{a}}$ & 0.62 \\
\hline $\mathrm{F} 3(\mathrm{pc} / \mathrm{ms})$ & $41.77 \pm 17.60$ & $18.02 \pm 14.09$ & $9.36 \pm 3.94$ \\
\hline$P$-value (from baseline) & $0.00^{\mathrm{a}}$ & 0.102 & 0.63 \\
\hline $\mathrm{F} 4(\mathrm{pc} / \mathrm{ms})$ & $16.01 \pm 8.58$ & $12.07 \pm 8.80$ & $8.38 \pm 3.41$ \\
\hline$P$-value (from baseline) & 0.246 & 0.535 & 0.18 \\
\hline
\end{tabular}

Abbreviations: A, orbital decompression procedure; B, extraocular muscle surgery; C, blephroplasty series; CAS, Clinical Activity Score; E, Exophthalmos (mm); F2, Flare 1 day after surgical intervention; F3, Flare 7 days after surgical intervention; F4, Flare 3 months after surgical intervention; IOP, intraocular pressure $(\mathrm{mm} \mathrm{Hg})$.

${ }^{\text {a }}$ Statistically significant.

TSH, FT3, and FT4 were within normal range. TRAb levels were $\leq 15 \mathrm{U} / 1$, except one patient with $\mathrm{TRAb}=34.5 \mathrm{U} / 1$.

Anterior segment examination on the first day postoperatively revealed dilated or mid-dilated pupil in 10 of 18 eyes following orbital decompression surgery. No other significant anterior chamber complications were noted in any patient during the course of follow-up.

Flare values, before surgical treatment (Figure 1), were significantly higher in the patients with GO $(14.03 \pm 8.45 \mathrm{pc} / \mathrm{ms})$ than in the control group $(7.89 \pm 3.56 \mathrm{pc} / \mathrm{ms})(P<0.001)$. Also, flare values were significantly higher in group $\mathrm{A}$ than in the group $\mathrm{C}$ (Figure 2) $(P<0.05)$.

The strongest correlation was found between baseline flare and IOP. The correlation coefficient equals 0.51 indicates a moderately strong relationship between the IOP and flare value $(P<0.05)$ in group A (Figure 2$)$.

CAS correlated with baseline flare in group A (56\%, $P<0.05)$ and in group B $(63 \%, P<0.05)$, and with $\mathrm{F} 4$ in group A $(61 \%, P<0.05)$ and in group B $(54 \%, P<0.05)$. There was no correlation between maximum CAS value and flare value in group $\mathrm{C}$.

Exophthalmos $(\mathrm{mm})$ correlated with baseline flare in group B $(36 \%, P<0.05)$.
Restrictive myopathy score in groups $\mathrm{A}, \mathrm{B}$, and $\mathrm{C}$ did not correlate with flare (F1, F2, F3, F4) $(P=0.7703)$.

In the group A (patients undergoing orbital decompression), flare was significantly increased 1 day after surgery $(P<0.0001)$ and 1 week later $(P<0.0001)$.

Normalization to preoperational value was reached 3 months after treatment $(P=0.2468)$.

In group $B$ (patients undergoing extraocular muscle surger) only early flare at first day after treatment was increased $(P<0.001)$. Later, there was no significant increase observed ( 1 week post-op: $P=0.1024 ; 3$ months post-op: $P=0.5357)$.

In group $C$ (patients undergoing eyelid surgery) there was no statistical difference in flare values at any point (1 day post-op: $P=0.6223$, 1 week post-op: $P=0.6260$; 3 month post-op: $P=0.1805$ ). Figure 3 shows flare values obtained during the study in three treatment groups $(\mathrm{A}, \mathrm{B}$, and $\mathrm{C})$.

\section{Discussion}

Intraocular complications of GO ( increased IOP, choroidal folds, optic nerve head oedema) have been known for long, but no data indicating intraocular inflammation have been published. Aqueous flare in 
a

Box-and-Whisker Plot

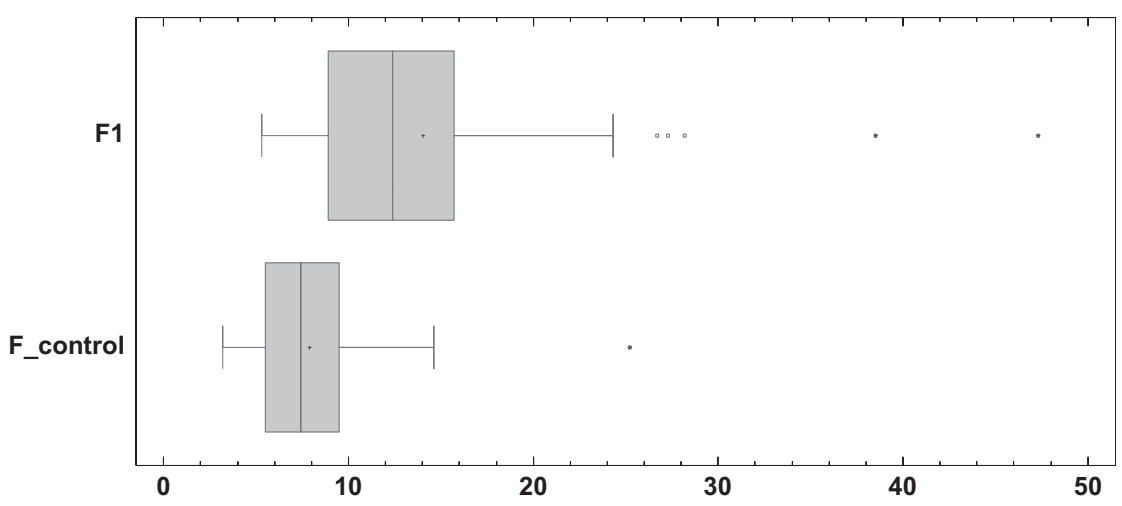

b

Box-and-Whisker Plot

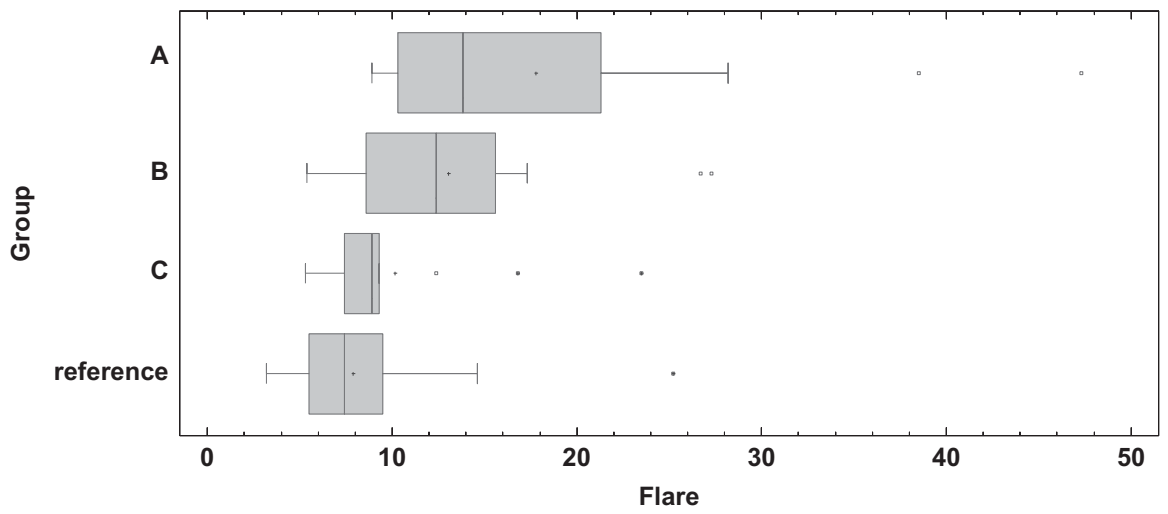

Figure 1 Baseline flare photometry values in the study groups. (a) Aqueous flare laser photometry in Graves' ophthalmopathy patients (F1-baseline flare value) versus control group (comparison of medians: Mann-Whitney (Wilcoxon) W-test to compare medians, $W=709.0 P<0.000001$ ). (b) Baseline aqueous flare by treatment group. In group A, flare is significantly higher than in group (b and c) and reference $(P<0.001)$. Moreover in group $B$, flare was significantly higher than in reference $(P<0.001)$. Results in group ( $b$ and c) were equal. Abbreviations: A, orbital decompression procedure; B, extraocular muscle surgery; $\mathrm{C}$, eyelid surgery.

Plot of Fitted Model

IOP $=\operatorname{sqrt}\left(383,774+0,273085^{\star} F 1^{\wedge} 2\right)$

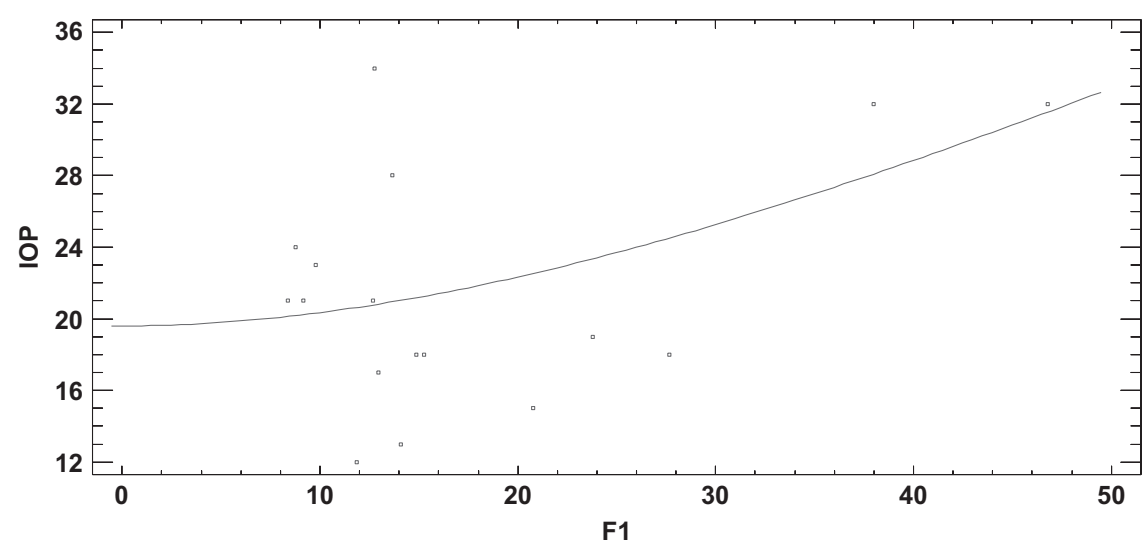

Figure 2 Intraocular pressure (IOP) is moderately strongly related $(P<0.05)$ to baseline flare value $(\mathrm{F} 1)$ in patients with Graves' ophthalmopathy. 


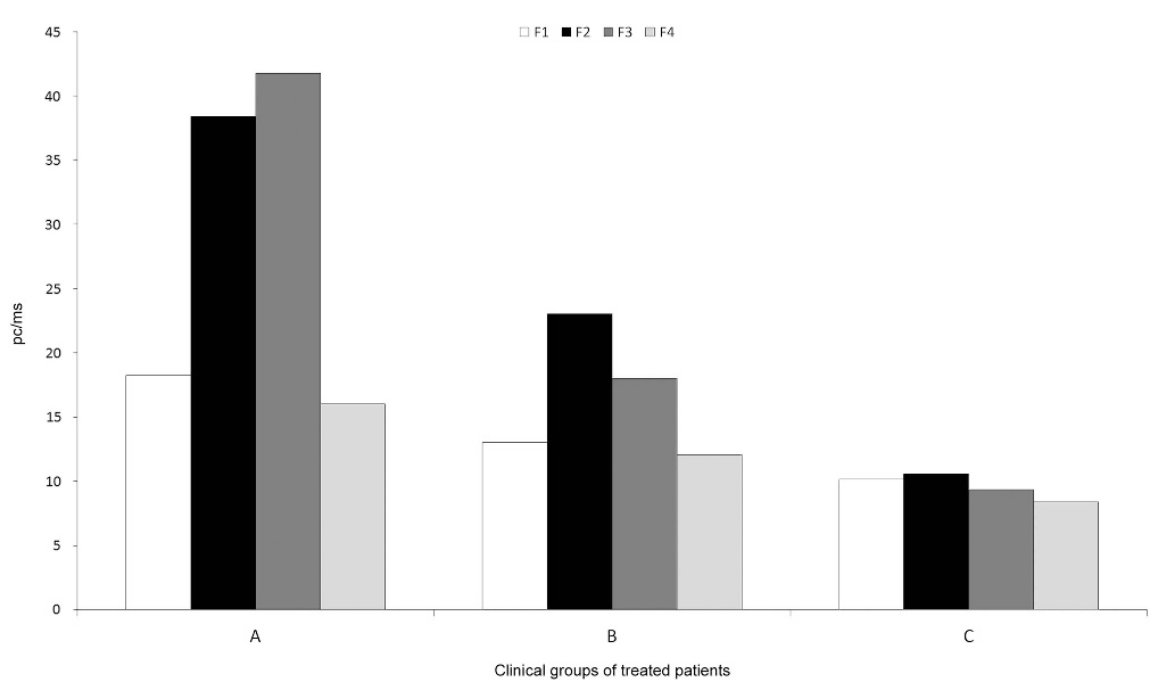

Figure 3 Aqueous flare before surgery (F1), 1 day after surgery (F2), 7 days after surgery (F3), and 3 months after surgery (F4) in the treatment groups (A, orbital decompression; B, extraocular muscles; C, eyelid surgery).

patients with GO and the effect of surgical rehabilitative procedures on $\mathrm{BAB}$ have not been studied in the past.

Increased baseline flare values, as compared with the control group, were found in patients with GO, especially those, who have undergone orbital decompression suffering from most significant exophthalmos, and those with the history of severe disease (high CAS) in the past. Also we found positive correlation between baseline flare and maximum CAS and exophthalmos, which are direct measures of the severity of ophthalmopathy. It is likely, therefore, that Graves' disease is the reason for the increased baseline flare values, we have observed.

The exact mechanism by which BAB is disrupted in GO is not known. Inflammatory process within the orbit and increased levels of free radicals may cause damage to the tight junctions of the capillaries of the ciliary body and iris. Another potential explanation is that altered hemodynamics caused by increased volume of the orbital tissue and increased episcleral venous and IOP may be responsible for the elevation of aqueous humour proteins.

Orbital inflammation in GO is well documented. Focal and diffuse mononuclear-cell infiltration occur within the extraocular and levator muscles, lacrimal glands, and orbital adipose tissues. These cells are primarily CD4+ T cells, but also CD8 + cells, B cells, plasma cells, and macrophages and type- 1 helper T cells, ${ }^{29,30}$ producing the cytokines interleukin-2, interferon- $\gamma$, and tumor necrosis factor, ${ }^{31}$ indicating cell-mediated immunity within the orbit. In later stages of the disease, type-2 helper T cells produce interleukin-4, interleukin-5, and interleukin-10. Macrophages, fibroblasts, and adipocytes produce other inflammatory mediators, including interleukins 1, 6, and 16 and transforming growth factor $\beta$ within the orbit. ${ }^{32}$ An increased oxidative stress has been observed in both acute and chronic phases of thyroid disease with raised tissue concentrations of reactive oxygen species. ${ }^{31}$

The physiological flare is dependent on two factors: protein filtration and aqueous humour production and drainage. ${ }^{33,34}$ Secretion of the $\mathrm{AH}$ and the entry of plasma proteins into anterior chamber are semiindependent events. ${ }^{5}$ Therefore, aqueous humour protein levels could increase in the absence of intraocular inflammation and breakdown of the tight junctions of the iris and ciliary epithelium.

Elevated IOP is one of the well-recognized features of ophthalmopathy and is more likely to occur in severe disease. This is probably why patients on IOP-lowering medication were found in the group undergoing orbital decompression and extraocular muscle surgery, and not in the group undergoing eyelid surgery. This last group of patients had milder form of the disease.

Alterations of aqueous humour dynamics in Graves' disease are not fully understood. One of possible mechanisms is that elevated episcleral pressure reduces outflow facility. ${ }^{35}$ Reducing aqueous humour outflow, with the same amount of protein being released from the iris stroma into the $\mathrm{AC}$, relative amount of protein increases. Inflammatory reaction present within the orbit and increased reactive oxygen species may affect anterior segment blood vessels ${ }^{36}$ and compromise tight junctions forming the $\mathrm{BAB}$.

The strongest correlation we found was between baseline flare and IOP, which strengthens the hypothesis that aqueous humour dynamics and IOP contribute to increased flare in patients with GO. 
This study was designed primarily to detect changes in BAB integrity following surgical rehabilitative procedures, and although higher flare values were found in patients receiving surgical treatment than controls, it is very difficult to draw conclusions regarding the whole population with GO. We aimed to construct control group to match not only age and sex, but also IOP, IOP treatment, and pseudophakia. It turned out impossible to match control group in respect of smoking, as severe ophthalmopathy is more likely to occur in smokers, high proportion of them was found in the study groups (A, B, C).

Alteration of the pupil lens valve for the posterior migration of the aqueous protein is expected in pseudophakic eye. We made an effort to construct control group that would be matched in respect with pseudophakia status.

Most of our patients remaining on IOP-lowering medication were receiving latanoprost Xalatan (Pfizer Labs, New York, NY, USA) and minority were on Combigan (Allergan Pharmaceuticals, Irvine, CA, USA). Increased flare values were found in patients remaining on prostaglandins analogues. ${ }^{37}$ Change was found in pseudophakic and aphakic eyes. ${ }^{38}$ Contrary findings were noted for phakic eyes with glaucoma. ${ }^{10}$ The effect of latanoprost on the BAB in eyes with inflammation may be distinct from its action on eyes without inflammation. ${ }^{39}$ It is, however, known that the increase in flare caused by prostaglandins is rather limited, ${ }^{10,37}$ as compared with the increase that we found before and after orbital decompression surgery.

Beta-blockers suppress aqueous production, therefore, relatively increase aqueous humour protein content, as protein secretion remains unchanged. Benzalkonium chloride also affects $B A B$, but this effect is small as compared with the effect of aqueous suppressant medication. ${ }^{40}$

The disruption of the $\mathrm{BAB}$ as a result of orbital decompression, and as a result of extraocular muscle surgery may be an indicator of intraoperative injury and may be used in the future to compare various techniques for orbital decompression in relation to the intraocular trauma.

During orbital decompression there is minimal direct trauma to the anterior segment of the eye as this is protected with a shield. There is significant trauma to the orbital retro-bulbar tissue and a degree of direct trauma to the globe. ${ }^{41}$ Postoperative oedema of the retro-orbital tissues causes increased episcleral venous pressure. It is a likely mechanism that influences $\mathrm{BAB}$, persistent beyond 7 days following surgery.

We found increased permeability of $\mathrm{BAB}$ in patients 1 day following extraocular muscle surgery. A potential explanation may be intraoperative trauma or anterior segment ischemia. This effect subsides within 7 days, as on day 7 the values returned to preoperative level.

Loss of BAB integrity may be a factor in elevation of IOP and long-term risk of glaucoma associated with GO. ${ }^{42}$

Our study demonstrated that lower and upper eyelid levator muscle recession has no effect on aqueous protein content, 1 day post surgery.

This study is difficult to blind, because GO, especially severe, is visible even to the non-medical observer. Also, the study is a single-centre one.

Further studies should evaluate whether technique and extent of orbital decompression find reflection in postoperative aqueous flare, and whether flare reflects the amount of orbital trauma inflicted during surgery, so it could be a valuable tool in comparing various surgical techniques used for orbital decompression.

\section{Conclusions}

Orbital decompression surgery disrupts blood-aqueous barrier. The integrity of $\mathrm{BAB}$ returns to preoperative status within 3 months. Extraocular muscle surgery mildly affects BAB integrity, and the effect subsides within 7 days. Eyelid surgery does not affect BAB.

\section{Summary}

\section{What was known before}

- Graves' Ophthalmopathy causes intraocular complications, such as increased IOP, astigmatism, and choroidal folds. $\mathrm{BAB}$ might be compromised in conditions not involving directly intraocular inflammation.

What this study adds

- BAB is compromised in patients with Graves' ophthalmopathy who undergo rehabilitative surgery. Orbital decompression and extraocular muscle surgery causes further disruption of BAB in Graves' Ophthalmopathy patients.

\section{Conflict of interest}

The authors declare no conflict of interest.

\section{Acknowledgements}

Medical University of Lodz grant 503/5-061-02/503-01.

\section{References}

1 Wiersinga WM, Smit T, van der Gaag R, Mourits M, Koornneef L. Clinical presentation of Graves' ophthalmopathy. Ophthalmic Res 1989; 21: 73-82. 
2 Bartalena L, Tanda ML. Immunotherapy for Graves orbitopathy: easy enthusiasm, but let's keep trying. J Endocrinol Invest 2006; 29: 1012-1016.

3 Bartalena L, Baldeschi L, Dickinson AJ, Eckstein A, Kendall-Taylor P, Marcocci C et al. Consensus statement of the European group on Graves' orbitopathy (EUGOGO) on management of Graves' orbitopathy. Thyroid 2008; 18: 333-346.

4 Shah SM, Spalton DJ, Smith SE. Measurement of aqueous cells and flare in normal eyes. Br J Ophthalmol 1991; 75: 348-352.

5 Freddo TF. A contemporary concept of the blood-aqueous barrier. Prog Retin Eye Res 2013; 32: 181-195.

6 Guillen-Monterrubio OM, Hartikainen J, Taskinen K, Saari KM. Quantitative determination of aqueous flare and cells in healthy eyes. Acta Ophthalmol Scand 1997; 75: 58-62.

7 Holland GN. A reconsideration of anterior chamber flare and its clinical relevance for children with chronic anterior uveitis (an American Ophthalmological Society thesis). Trans Am Ophthalmol Soc 2007; 105: 344-364.

8 Kong X, Liu X, Huang X, Mao Z, Zhong Y, Chi W. Damage to the blood-aqueous barrier in eyes with primary angle closure glaucoma. Mol Vis 2010; 16: 2026-2032.

9 Nguyen NX, Schonherr U, Kuchle M. Aqueous flare and retinal capillary changes in eyes with diabetic retinopathy. Ophthalmologica 1995; 209: 145-148.

10 Arcieri ES, Pierre Filho PT, Wakamatsu TH, Costa VP. The effects of prostaglandin analogues on the blood aqueous barrier and corneal thickness of phakic patients with primary open-angle glaucoma and ocular hypertension. Eye (Lond) 2008; 22: 179-183.

11 Kahraman G, Amon M, Franz C, Prinz A, Abela-Formanek C. Intraindividual comparison of surgical trauma after bimanual microincision and conventional small-incision coaxial phacoemulsification. J Cataract Refract Surg 2007; 33: 618-622

12 Larsson LI, Nuija E. Increased permeability of the bloodaqueous barrier after panretinal photocoagulation for proliferative diabetic retinopathy. Acta Ophthalmol Scand 2001; 79: 414-416.

13 Wiersinga WM, Perros P, Kahaly GJ, Mourits MP, Baldeschi L, Boboridis $\mathrm{K}$ et al. Clinical assessment of patients with Graves' orbitopathy: the European Group on Graves' Orbitopathy recommendations to generalists, specialists and clinical researchers. Eur J Endocrinol 2006; 155: 387-389.

14 McKeag D, Lane C, Lazarus JH, Baldeschi L, Boboridis K, Dickinson AJ et al. Clinical features of dysthyroid optic neuropathy: a European Group on Graves' Orbitopathy (EUGOGO) survey. Br J Ophthalmol 2007; 91: 455-458.

15 Freddo TF, Neville N, Gong H. Pilocarpine-induced flare is physiological rather than pathological. Exp Eye Res 2013; 107: $37-43$

16 Gamblin GT, Harper DG, Galentine P, Buck DR, Chernow B, Eil C. Prevalence of increased intraocular pressure in Graves' disease-evidence of frequent subclinical ophthalmopathy. N Engl J Med 1983; 308: 420-424.

17 Ohtsuka K. Intraocular pressure and proptosis in 95 patients with Graves ophthalmopathy. Am I Ophthalmol 1997; 124: 570-572.

18 Gong H, Freddo TF. The washout phenomenon in aqueous outflow-why does it matter? Exp Eye Res 2009; 88: 729-737.

19 Looi AL, Luu CD, Wong TY, Seah LL, Rootman J. Factors associated with decompression and strabismus surgery in thyroid eye disease. Ann Acad Med Singapore 2005; 34: 154-157.

20 Limawararut V, Valenzuela AA, Sullivan TJ, McNab AA, Malhotra R, Davis G et al. Cerebrospinal fluid leaks in orbital and lacrimal surgery. Surv Ophthalmol 2008; 53: 274-284.

21 Norris JH, Ross JJ, Kazim M, Selva D, Malhotra R. The effect of orbital decompression surgery on refraction and intraocular pressure in patients with thyroid orbitopathy. Eye (Lond) 2012; 26: 535-543.

22 Flanders M, Hastings M. Diagnosis and surgical management of strabismus associated with thyroid-related orbitopathy. J Pediatr Ophthalmol Strabismus 1997; 34: 333-340.

23 Ino-ue $\mathrm{M}$, Shirabe $\mathrm{H}$, Yamamoto $\mathrm{M}$. Blood-aqueous barrier disruption in experimental anterior segment ischemia in rabbit eyes. Ophthalmic Res 1999; 31: 213-219.

24 Neugebauer A, Kaszli FA, Diestelhorst M, Russmann W. Do standard procedures in squint surgery influence the blood-aqueous barrier? Ophthalmic Surg Lasers 1997; 28: 570-573.

25 Mourits MP, Koornneef L, Wiersinga WM, Prummel MF, Berghout A, van der Gaag R. Clinical criteria for the assessment of disease activity in Graves' ophthalmopathy: a novel approach. Br J Ophthalmol 1989; 73: 639-644.

26 Onodera T, Gimbel HV, DeBroff BM. Aqueous flare and cell number in healthy eyes of Caucasians. Jpn J Ophthalmol 1993; 37: 445-451.

27 Kozakiewicz M, Szymor P. Comparison of pre-bent titanium mesh versus polyethylene implants in patient specific orbital reconstructions. Head Face Med 2013; 9: 32.

28 Kozakiewicz M, Elgalal M, Loba P, Komunski P, Arkuszewski P, Broniarczyk-Loba A et al. Clinical application of 3D pre-bent titanium implants for orbital floor fractures. J Craniomaxillofac Surg 2009; 37: 229-234.

29 Pappa A, Calder V, Ajjan R, Fells P, Ludgate M, Weetman $\mathrm{AP}$ et al. Analysis of extraocular muscle-infiltrating T cells in thyroid-associated ophthalmopathy (TAO). Clin Exp Immunol 1997; 109: 362-369.

30 Eckstein AK, Quadbeck B, Tews S, Mann K, Kruger C, Mohr $\mathrm{CH}$ et al. Thyroid associated ophthalmopathy: evidence for $\mathrm{CD} 4(+)$ gammadelta T cells; de novo differentiation of RFD7 $(+)$ macrophages, but not of RFD1 $(+)$ dendritic cells; and loss of gammadelta and alphabeta T cell receptor expression. Br J Ophthalmol 2004; 88: 803-808.

31 Tsai CC, Cheng CY, Liu CY, Kao SC, Kau HC, Hsu WM et al. Oxidative stress in patients with Graves' ophthalmopathy: relationship between oxidative DNA damage and clinical evolution. Eye (Lond) 2009; 23: 1725-1730.

32 Kumar S, Bahn RS. Relative overexpression of macrophagederived cytokines in orbital adipose tissue from patients with graves' ophthalmopathy. J Clin Endocrinol Metab 2003; 88: 4246-4250.

33 Oshika T, Araie M, Masuda K. Diurnal variation of aqueous flare in normal human eyes measured with laser flare-cell meter. Jpn J Ophthalmol 1988; 32: 143-150.

34 Sawa M, Tsurimaki Y, Tsuru T, Shimizu H. New quantitative method to determine protein concentration and cell number in aqueous in vivo. Jpn J Ophthalmol 1988; 32: 132-142.

35 Haefliger IO, von Arx G, Pimentel AR. Pathophysiology of intraocular pressure increase and glaucoma prevalence in thyroid eye disease: a mini-review. Klin Monbl Augenheilkd 2010; 227: 292-293. 
36 Bahn RS. Graves' ophthalmopathy. N Engl J Med 2010; 362 726-738.

37 Cellini M, Caramazza R, Bonsanto D, Bernabini B, Campos EC. Prostaglandin analogs and blood-aqueous barrier integrity: a flare cell meter study. Ophthalmologica 2004; 218: 312-317.

38 Arcieri ES, Santana A, Rocha FN, Guapo GL, Costa VP. Blood-aqueous barrier changes after the use of prostaglandin analogues in patients with pseudophakia and aphakia: a 6-month randomized trial. Arch Ophthalmol 2005; 123: 186-192.

39 Kiuchi Y, Okada K, Ito N, Hayashida Y, Fukui K, Ohnishi T et al. Effect of a single drop of latanoprost on intraocular pressure and blood-aqueous barrier permeability in patients with uveitis. Kobe J Med Sci 2002; 48: 153-159.

40 Stevens AM, Kestelyn PA, De Bacquer D, Kestelyn PG. Benzalkonium chloride induces anterior chamber inflammation in previously untreated patients with ocular hypertension as measured by flare meter: a randomized clinical trial. Acta Ophthalmol 2012; 90: e221-e224.

41 Verity DH, Rose GE. Acute thyroid eye disease (TED): principles of medical and surgical management. Eye (Lond) 2013; 27: 308-319.

42 Cross JM, Girkin CA, Owsley C, McGwin G Jr. The association between thyroid problems and glaucoma. Br J Ophthalmol 2008; 92: 1503-1505. 